\title{
An Electronic Traceability System for an Indonesian Fresh Fruit Supply Chain
}

\author{
Iwan Vanany ${ }^{1}$, Kuntoro Boga Andri ${ }^{2}$, Ronny Mardiyanto ${ }^{3}$, Niniek Fajar Puspita ${ }^{4}$, \\ and Wiwik Heny Winarsih ${ }^{5}$
}

\begin{abstract}
Nowdays, traceability system for agriculture comodity is mandatory requirements in some countries such as Japan, United States, and all European countries. All export agricultural companies must applied traceability system to fulfill the mandates of goverments market requirements. Traceability system also has beneficials to reduce products return and improve efficiencies and effectiveness their inventory. Electronic traceability system is relatively new and is believed by many experts to have the advantages than paper-based traceability system such as: integration of data to multiple users, the accuracy of data input and control and monitoring easier and faster. Although the recent problems of traceability becomes the important issues in food and agriculture supply chain, but a few researchers to design and implement electronic traceability system especially to integrate multi-user and in supply chain contex. This paper develop the electronic traceability system products including software for electronic traceability system and barcode technology. Unified Modelling Language (UML) is used to design traceabilty system model that was described a usecase, state and sequence diagram. Based on these models, electronic traceability system was developed by adopting XAMPP control panel. Indonesian mangosteen and manggo fruits were chosen as a case study in order to validate electronic traceability system. The results showed that the electronic traceability system product is relatif support to helps members of supply chain to complete their traceability system capabilities for the benefit of mangosteen and mango exports.
\end{abstract}

Keywords_ — Electronic traceability system and Indonesian fresh fruits products.

\section{INTRODUCTION}

$\mathrm{T}$ The food industry is a vital sector for the national economy, social stability and export competitiveness of agricultural commodities. The availability of sufficient, adequate quality, affordable price and security of the disease, hazardous materials are important factors in supporting food safety in food industry, export competitiveness, and create economic and social resilience. In many ways, food products have higher levels of vulnerability compare with other products. Various events such as the risk of insufficient availability of food, food containing hazardous materials, Food consumed that have expired so often appear as a result of poisoning in the news media. Number of occurrences of livestock diseases (avian flu, mad cow, etc), food contamination, adulteration, the issue of halal and other production issues also fueled the need to have the ability to trace product back in the event of an underisable.

National food industry (including beverages and tobacco) is a strategic industry that is able to donate the value of national exports for Indonesia's second largest [1]. Export competitiveness of agricultural commodities is crucial problems faced by business people and government. A few actors Indonesian agricultural

${ }^{1}$ Iwan Vanany is with Departement of Industrial Engineering, Faculty of Industrial Technology, Institut Teknologi Sepuluh Nopember, Surabaya,60111, Indonesia. E-mail: vanany@ie.its.ac.id.

${ }^{2}$ Kuntoro Boga Andri is with East Java Assessment Institute for Agricultural Technology, Malang, Indonesia, Indonesia. E-mail: kuntoro@gmail.com.

${ }^{3}$ Ronny Mardiyanto is with Departement of Electrical Engineering, Faculty of Industrial Technology, Institut Teknologi Sepuluh Nopember, Surabaya, 60111, Indonesia. E-mail: ronny@electeng.its.ac.id.

${ }^{4}$ Niniek Fajar Puspita is with Departement of Chemical Engineering, Faculty of Industrial Technology, Institut Teknologi Sepuluh Nopember, Surabaya, 60111, Indonesia. E-mail: niniek.fp@gmail.com.

${ }^{5}$ Wiwik Heny Winarsih is with Research and Development Agency, East Java Government, Surabaya, Indonesia. E-mail: whwinarsih@yahoo.com. commodities have capability to penetrate the export markets such as the United States, the States-European Union and Japan. One of the problems is many Indonesian food exports doesn't have a good traceability system as a legal requirement. Japan introduced the guidelines of the food traceability system in 2003 [2]. United States also introduced traceability system with 21CFR820 regulations in 2004 [3]. EU General Food Law delivered legal requirement a traceability system for agricultural commodities to ensure food safety in products in 2005 [4].

The business players in export agricultural commodities also get other benefits if they implement traceability system such as: (1) to support food safety, (2) determine the nature and delivery of safe and secure products, (3) facilitates tracing product recall, (4) help protect their brands from counterfeiting, (5 ) facilitate the verification of the product by the government, and can create effectiveness and efficiency of inventory management across the supply chain members (Alfaro and Rabade, 2009). The implementation of traceability system is as a strategic system to increase the capabilities of the business players in export agricultural commodities.

Traceability system is a complex system because it represents the four components, namely: (1) process, (2) work organization, (3) information, and (4) technology [5]. On the other hand, the integration process of the traceability system is not only the organization but also the internal processes external to the organization. Kim et al [6] believe that the fundamental of the traceability system is the ability to trace the product and the process. European Standard [7] also states that products and processes are the main entities that need to be described and considered. This indicates that the products (especially the flow of products) and processes are required to make the product is an integral part and should be used as basis in establishing traceability system. Therefore, the efforts to integrate the process and 
identify three components are become important for players in food industry.

Electronic traceability system is relatively new and many experts believed that it has the advantages than the paper-based traceability system such as: (1) data integration for multi-user, (2) the accuracy of data input and (3) control and monitoring easier and faster done. The existence of the following software network, some users who are involved from the receipt of raw materials to the final product received by consumers can be mutually integrated with each other. Accuracy of input data that can be realized as fast as there is automated identification technologies used in electronic traceability system. This automation also reduces the labor for recording trace data is not required. Control and monitoring will also be easily and quickly done by managers when transaction and summary data are used the software.

The disadvantage of the electronic traceability system is a significant investment required by the busines players of export agricultural commodities than with paper-based traceability system. Electronic traceability system requires software and automation identification technologies such as barcode reader and sticker than paper-based traceability system that only uses manual logbook. However, it is believed that the economic value of value compared with the ratio between the benefits exceed the cost of investment is due to the amount of benefit greater than the cost of investment.

Although, the problem of traceability becomes an important issue in the food supply chain and enough attention from researchers , but not much research design following up implementation of electronic traceability system specifically integrates multi-user and in the context of the food supply chain. This research is expected to contribute to increasing the capability of the national food industry to trace food products flows. Ability have traceability systems that are reliable and smart systems will be able to support the improvement of food quality and food safety such as HACCP ( hazard analysis critical control point) and ISO 2200, ISO 22005 for especially for traceability in the feed and food chain . The customer and the industry will be equally benefited. Customers ensure the food products will be free from the risk of undesirable foods, the industry could also implement more efficient business processes, include to reduce finished products inventory.

This study designed and implemented electronic wake traceability system as well as reviewing the implementation and regulation. The 3 main goals to be achieved, namely: (1) develop the software for electronic traceability systems and (2) implement the electronic traceability system in one case.

\section{METHOD}

This phase of the research activities is sequence and related to one another. The results of the previous stage will be the basis for the next stages. First, literature studies and field observations conducted to obtain state of the art that is more complete than a traceability system for food supply chain and to map the structure of the supply chain for export agricultural commodities. Mapping the structure of the national food supply chain aims to recognize the type, amount, and the linkages between members/entities of the food industry supply chain using focus group discussions. Second, designing for traceability system was developed. Third, electronic traceability system software was produced. Finally, electronic traceability system software should be tested and applied some users (farmers, fruits collectors and exporters).

\section{RESULT AND DISCUSSION}

This study developed electronic traceability system for mangosteen from farmers until exporters in East Java. Exports of Mangosteen fruit having problems because of the contents in the fruit export perstisida. Before we developed electronic traceability system software, mangosteen supply chain was mapped in Figure 1. Four players in mangosteen supply chain such as farmers, fruits collectors, exporters and customers. In farmer players, some activities should be carried out as harvesting, packing and delivery. After fruits collectors receive mangosteen, sorting, grading, packing and delivery to exporters should be carried out. In exporters, a few activities should be undertaken such as receiving and delivering.

There are 2 types of labels that were used such as product and shipping labels. In product labels, the information that should be used such as: (1) kind of fruit, (2) bar code products and other important information. Product and shipping labels were be distinguished for the mangosteen fruit. In figure 2, products label is shown. Product code fruit was converted into a barcode symbol with GS-128 type of code that will be easier for users to entry data. Shipping labels use Serial Shipping Container Code (SSCC) to support the design of electronic traceability system. Code shipping labels was also be used GS-128 barcode symbols (see figure 3).

The Use Case Diagram in UML is a useful approach to capture both operation flows and most requirements of system functions (Wu et al, 2006). We developed Use Case Diagram of electronic traceability system for some users in mangosteen supply chain such as farmers, fruits collectors, exporters and customers in figure 4.

A State Diagrams and Sequence Diagrams for each process was also developed that was used as a basic to develop electronic traceability system software. Based on mapping of busines process, some activites in each player has been idetified such as registration, printing for shipping label, delivery and tracking to fruit collectors in farmer players. Some processes of traceability for fruit collectors are receiving, sorting, printing for product label, printing for shipping label, delivery and tracking. In exporters players are receiving, printing for product label, printing for shipping label, delivery and tracking.

Based on Use Case Diagram, State Diagram and Sequence diagram, electronic traceability system software was developed by adopting XAMPP control panel. In Figure 5 is showed the main intercase electronic traceability systems for mangosteen. The interface for shipping menu in farmer players is also showed in Figure 6.

\section{CONCLUSION}

Design of electronic traceability system was developed using some diagrams in UML methods such as Use Case diagrams, State diagrams and Sequence diagrams for 
each process. The process required is the process (1) registration, (2) printed shipping label (farmer), (3) delivery (farmer), (4) tracking, (5) receiving, (6) product label printing (collectors and exporters) , (7) printed shipping label (collectors and exporters), and (8) delivery (collectors and exporters).

Before doing electronic design traceability system, it first needs to consider the location of check points to perform data input and tracking. Barcode label located on the product and shipping label are very helpful to enter input data and perform a search for the users in each members of mangosteen supply chain.

Electronic traceability system (ETS) software for mangosteen was developed to improve capabilities mangosteen supply chain players. Based on Mangosteen the supply chain mapping, the user ETS depends on the type of entity involved in traceability. The mangosteen results show that mangosteen users are (1) farmers, (2) fruits collectors, (3) exporters and (4) consumers. Some farmers and fruit collectors pointed out that used electronic traceability system softwares relatively easy and supports theirs works for traceability and others jobs.

\section{REFERENCES}

[1]. Yustika (2011), Pemerintah Perlu Siapkan Pohon Industri, http://bataviase.co.id /node/614156

[2]. FMRIC (2008), Handbook for Introduction of Food Traceability Systems Guidelines for Food Traceability) http://www.maff.go.jp/j/syouan/seisaku/trace/pdf/handbook _en.pdf

[3]. FDA (2004), Regulation 21CFR820, 2004. U.S. Food and Drug Administration, Title 21: Food and Drugs, Subchapter H: Medical Devices, Part 820 Quality System Regulation. $<$ http://www.accessdata.fda.gov/scripts/cdrh/cfdocs/cfcfr/ CFRSearch.cfm ?CFRPart $=820>$.

[4]. Engelseth, P., (2009), Food product traceability and supply network integration, The Journal of Business and Industria Marketing, 24 (5-6), 421-430

[5]. Verdenius (2006), Using traceability systems to optimize business performance, Smith and Furness (Editor), Improving traceability in food processing and

[6]. Kim, H.M., Fox, M.S., Gruninger, M., (1995), Ontology of quality for enterprise modelling. In: IEEE Proceedings of WETICE, Los Albamitos, CA, USA, 105-116.

[7]. European Standard (1995). [EN ISO 8402:1995, Point 3.16] European Committee for Standardization (CEN).

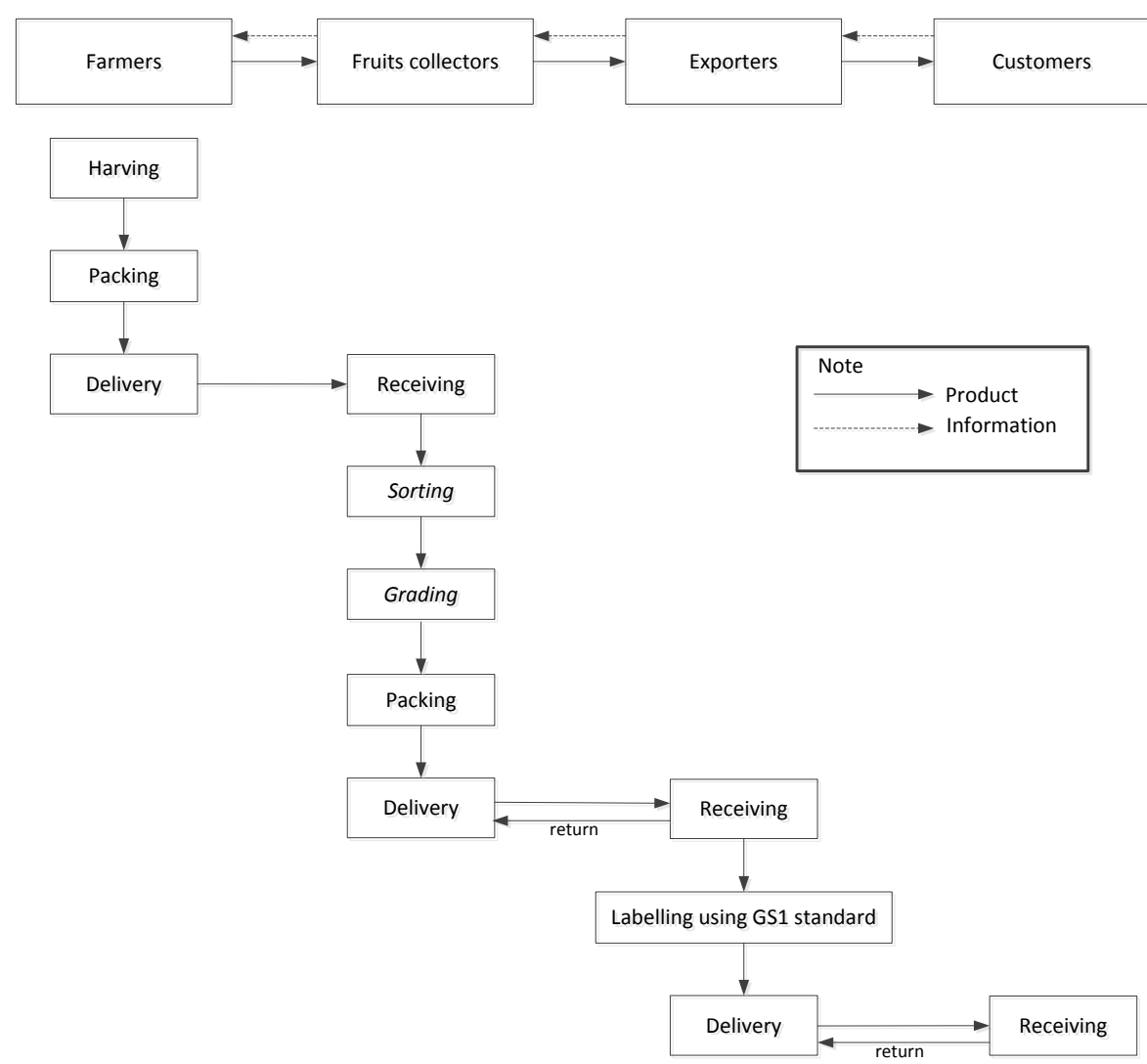

Figure 1. Mangosteen supply chain

\begin{tabular}{|c|c|}
\hline \multirow{2}{*}{$\begin{array}{c}\text { Manggis } \\
\text { Tipe A }\end{array}$} & Size Lot: 1 \\
\hline & No Lot: 1 \\
\hline \multicolumn{2}{|c|}{ Tanggal Kadaluarsa: 2013-07-31 } \\
\hline \multicolumn{2}{|c|}{ Barcode Produk Pengepul } \\
\hline & \\
\hline 20101 & 30718 \\
\hline
\end{tabular}

Figure 2. Product labels

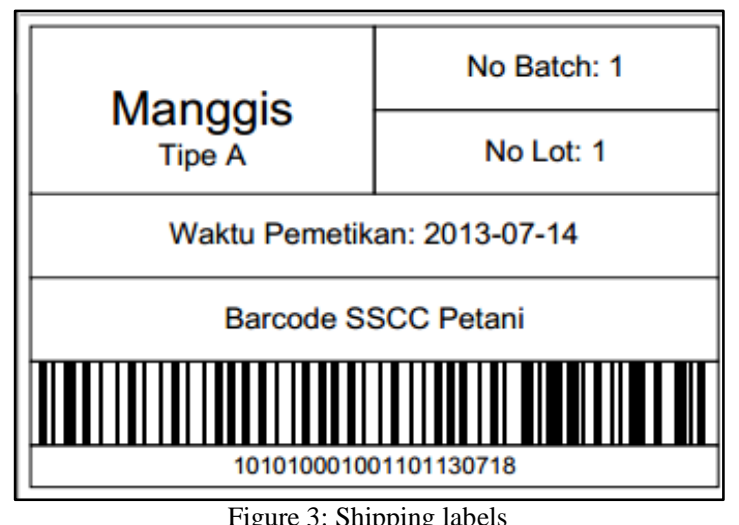

Figure 3: Shipping labels 

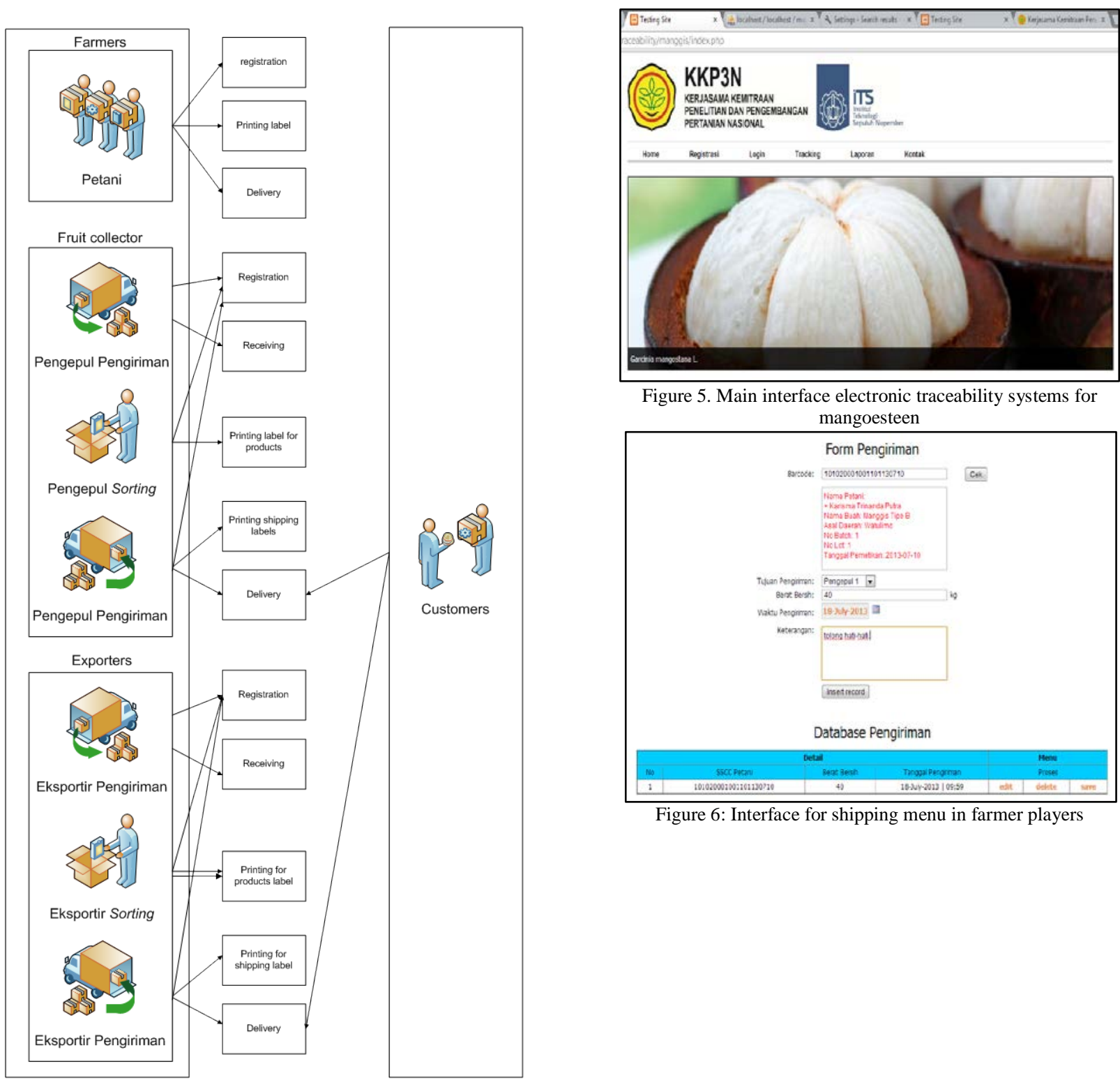

Figure 5. Main interface electronic traceability systems for

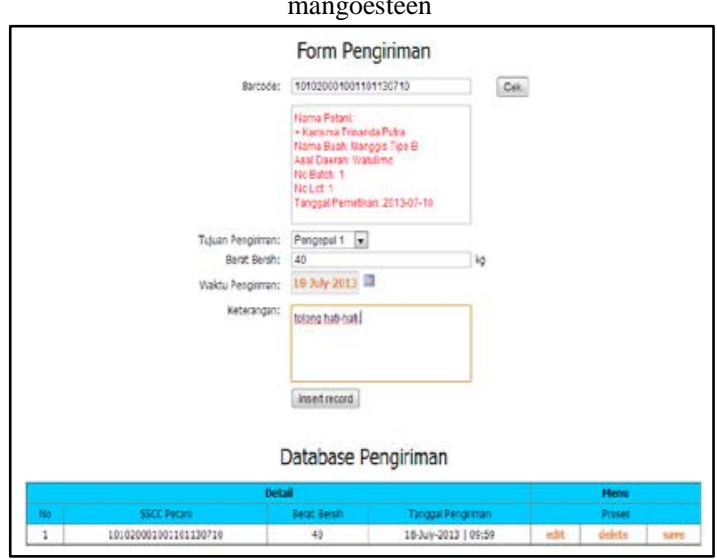

Figure 6: Interface for shipping menu in farmer players

Figure 4. Use Case Diagram for Mangosteen traceability systems 